$\begin{array}{ll} & \text { Etnográfica } \\ \text { etnográfica } & \text { Revista do Centro em Rede de Investigação em }\end{array}$

Antropologia

vol. $16(1) \mid 2012$

Vol. $16(1)$

\title{
Renato Miguel do Carmo e José Alberto Simões (orgs.), A Produção das Mobilidades: Redes, Espacialidades e Trajectos
}

\author{
Rita d'Ávila Cachado
}

\section{(2) OpenEdition}

Journals

\section{Edição electrónica}

URL: https://journals.openedition.org/etnografica/1440

DOI: $10.4000 /$ etnografica. 1440

ISSN: 2182-2891

\section{Editora}

Centro em Rede de Investigação em Antropologia

Edição impressa

Data de publição: 1 fevereiro 2012

Paginação: 203-205

ISSN: 0873-6561

\section{Refêrencia eletrónica}

Rita d'Ávila Cachado, «Renato Miguel do Carmo e José Alberto Simões (orgs.), A Produção das

Mobilidades: Redes, Espacialidades e Trajectos», Etnográfica [Online], vol. 16 (1) | 2012, posto online no dia 06 março 2012, consultado o 12 fevereiro 2022. URL: http://journals.openedition.org/etnografica/ 1440 ; DOI: https://doi.org/10.4000/etnografica. 1440

\section{(c) (7) (8)}

Etnográfica is licensed under a Creative Commons Attribution-NonCommercial 4.0 International License. 
Renato Miguel do Carmo e José Alberto Simões (orgs.)

\section{A PRODUÇÃO DAS MOBILIDADES: REDES, ESPACIALIDADES E TRAJECTOS \\ Lisboa, Imprensa de Ciências Sociais, 2009, 272 páginas, \\ ISBN: 978-972-67 1-250-3.}

A perceção da rapidez, dos fluxos, do movimento nas suas múltiplas formas tem conduzido os investigadores em ciências sociais a deterem-se no conceito de mobilidade. Nascido da história urbana e da história das tecnologias associadas aos transportes, desenvolvido no seio das reflexões sobre migrações, o estatuto alcançado pela mobilidade no último decénio permitiu-lhe ser distendido para analisar temas aparentemente díspares, como acontece no livro A Produção das Mobilidades: Redes, Espacialidades e Trajectos. O livro em revista nasceu do encontro dos autores num painel do VI Congresso Português de Sociologia, mas os organizadores da coletânea não estão apenas preocupados com a publicação das atas. Mais do que pretender uma revisão do conceito, esta é uma coletânea dedicada à compreensão dos modos de produção das mobilidades. Se na introdução ao livro os organizadores parecem procurar um sentido de unidade entre as componentes, o exercício de recensear esta obra é antes buscar o sentido específico da mobilidade em cada um dos capítulos.
Tim Cresswell abre a edição, defendendo que "a não novidade das mobilidades é importante porque nos ajuda a resistir ao sabor da tecnofilia e ao gosto pelo agora que marca qualquer campo com o prefixo 'novo'” (p. 36). Juntamente com Vincent Kaufmann e John Urry noutros registos e desde o início dos anos 2000, Tim Cresswell é um dos autores que instala a discussão sobre a produção das mobilidades (cf. 2001, "The production of mobilities", New Formations, 43: 11-25) e é, por isso, um excelente arauto desta obra coletiva.

"Do espaço abstrato compósito: refletindo sobre as tensões entre mobilidades e espacialidades", de Renato do Carmo, é um texto que investe na necessidade de ultrapassar categorias binárias, através da análise das tensões entre mobilidades e espacialidades, dinâmicas e assimetrias, despolitização/politização, fazendo com que mobilidade se aproxime de dinâmica cultural. De facto, a mobilidade enquanto conceito tem muito a ganhar se, à sua história marcada pelo urbanismo e pelo cruzamento recente com a mobilidade social, juntarmos a dinâmica cultural, uma vez que só uma formulação conjuntural permite expor realidades diversas como as apresentadas no restante volume.

Segue-se o texto de Frédéric Vidal, "A mobilidade residencial como objeto da história urbana...", com inestimável preocupação metodológica, abordando uma vertente rara mas promissora da mobilidade. 
Vidal defende que as mobilidades urbanas valem mais pela lição de método que podem oferecer do que pelos resultados em si (cf. Bernard LePetit e Denise Pumain (orgs.), 1993, Temporalités Urbaines, Paris, Anthropos) e revê o conceito de bairro para poder analisar a estabilidade residencial, aludindo à insuficiência dos métodos quantitativos para estudar bairros.

Em "Redes, Internet e hip-hop: redefinindo o espaço dos fluxos", de José Alberto Simões, a mobilidade emerge como resultado de pesquisa, embora a forma como o convoca surja como uma adaptação da análise sobre a globalização e o seu par dicotómico, a localização. Simões defende que no hip-hop atual, apesar da desterritorialização provocada pela Internet, continua a haver localização deste fenómeno. A seguir, "Movimentos da imagem no graffiti: das ruas da cidade para os circuitos digitais", de Ricardo Campos, questiona "o que terá o graffiti a ver com a ideia de mobilidade?" (p. 92). O texto indica que a mobilidade do graffiti está na sua função de comunicar e difundir estilos, e instaura a imagem de "fugacidade" como o que o percorre. Interessante é a análise do efeito de fixação conseguido pela fotografia registada na Internet, aqui como "dispositivo de empowerment"; neste sentido, a ligação com a mobilidade prender-se-á com a mobilidade social.

O livro prossegue com o turismo. Maria João Cordeiro é autora de "Em busca de um 'tempo parado'...", onde avalia como a mobilidade pode ser questionada ao estudar fenómenos turísticos atuais, sem cair na tentação da viagem como equivalente a mobilidade per se. Aprendemos sobre o imaginário do outro, neste caso turistas alemães, que procuram na realidade portuguesa uma cultura e costumes supostamente parados no tempo. Tal como no capítulo anterior, é a fixação o fulcro da análise. A presença destes sinais na análise das mobilidades faz reconhecer a utilidade de interpretações recentes que consideram tão importante a imobilidade como a mobilidade.

É ainda sobre fixação - inesperada que nos fala André Nóvoa em "A 'carrinha' dos músicos em tournée..." E pergunta-se: onde está a mobilidade, mesmo em viagem, quando os atores sociais se atêm aos lugares culturalmente seguros? Cruzando-a com os conceitos de lugar, fixidez e território, Nóvoa explica a produção das (i)mobilidades entre artistas numa tournée, que de mobilidade apenas tem os quilómetros percorridos, e a carrinha surge como "cápsula que envolve e fecha os músicos dentro de uma cultura" (p. 146).

A estrada continua a ser foco de atenção em "Os profissionais das artes do espetáculo 'na estrada'...", de Cristina Farinha. Aqui, é de novo a mobilidade social que, associada à realização pessoal, aproxima a autora duma mobilidade centrada nas ambições dos sujeitos. Competências são cruzadas com aspirações, uma vez que aquelas "são uma exigência face à pluralidade multifacetada de oportunidades" (p. 161), fazendo eco com outras profissões com novas exigências. A maior competição na atualidade amplia a partilha de conhecimentos entre os artistas retratados. Este é um ponto de vista positivo sobre as atuais competências necessárias para a internacionalização ou, melhor, como os artistas superam as suas dificuldades. Farinha defende que "esta reflexão pode ser alargada a outros profissionais criativos e intelectuais" (p. 174), introduzindo o capítulo seguinte de Ana Delicado, “'Lá fora com um pé cá dentro': ligações dos cientistas expatriados ao sistema científico português", que aborda a manutenção dos contactos dos investigadores transmigrantes com a terra de origem, abrindo um campo de comparação com outros transmigrantes classicamente analisados nos estudos de migrações. Interessante é a tipologia experimentada através de perfis dos cientistas em quatro clusters. 
Ressalta uma grande variedade, sem hipótese de homogeneização.

Através de dados sobre alguns dos jogadores de futebol mais internacionais, segue-se a análise de uma interessante analogia entre cidades globais e "clubes globais" em "Porque todos os 'rebeldes' falam português?...", de Carmen Rial. A autora resgata Freyre para refletir sobre a imagem idealizada destes jogadores da América do Sul, e destaca que a Europa apresenta uma diversidade de construções retóricas de raça e origem étnica, retomando a necessidade de refletir sobre as configurações destes discursos, trazendo a mobilidade para a equação. As viagens destes jogadores realçam a mobilidade social - a viagem como deslocação geográfica e na hierarquia social (com Lévi-Strauss).

José Mapril, em “'Os novos VIP’: políticas de mobilidade, emigração e nação no Bangladesh contemporâneo", detém-se num assunto pouco abordado na área das migrações - é que às vezes são os Estados que promovem a emigração. Mapril foi atrás dessa história no Bangladesh, seguindo os discursos políticos e institucionais para analisar o contexto em causa. $\mathrm{O}$ objetivo é acrescentar a emigração às demais preocupações da governamentalidade, uma vez que, como neste caso, foi mesmo institucionalizada uma indústria de exportação de mão de obra, que acaba por ser o garante da desejada "modernidade" no Bangladesh e que faz destes emigrantes os novos VIP.

O último capítulo equaciona a mobilidade através da análise da fundação de uma Igreja. "Circunscrição moral: mobilidade, diáspora e configurações doutrinais na Igreja Tokoísta (Angola)", de Ruy Blanes, leva-nos a conhecer o processo de crescimento da Igreja em causa. Este é um processo que depende da mobilidade dos seus principais representantes. Religião e migrações são aqui cruzadas com a ajuda das políticas estatais. Sem falar de poder nem de controlo, é a mobilidade no seu estatuto conceptual contemporâneo que permite cruzar dinâmicas culturais distintas.

Nesta coletânea, quando a mobilidade aparece como parte do método de pesquisa, os artigos resultam mais seguros; quando a mobilidade surge como possibilidade interpretativa, provocam uma sensação de insegurança analítica. É possível que esta situação ocorra justamente porque a mobilidade atravessa uma recomposição conceptual e porque a sua história é dificilmente abarcável seguindo apenas uma disciplina de cada vez. A mobilidade e suas dimensões, como exemplifica bem este livro, requer interdisciplinaridade.

\section{Rita d'Ávila Cachado}

CIES-IUL, Portugal

ritacachado@gmail.com
D. Ann Herring

e Alan C. Swedlund (orgs.)

PLAGUES AND EPIDEMICS:

INFECTED SPACES, PAST

AND PRESENT

Oxford e Nova Iorque, Berg, 2010 ,

417 páginas,

ISBN: 978-184-788-547-0.
Epidemias e pestes são o fio condutor das reflexões que compõem este trabalho coletivo, resultado do encontro realizado em Tucson, Arizona (EUA), em setembro de 2007, entre antropólogos e outros investigadores que trabalham sobre questões sociais da saúde. Trata-se de um conjunto de artigos sobre doenças tão diferentes como a gripe 